Commonplace • Series 1.3: Global Transition to Open

\title{
A Reflection about Equity in the Open Access from the Consorcio Colombia
}

Nicolás Duque-Buitrago ${ }^{1}$

${ }^{1}$ University of Caldas (Colombia)

Published on: Nov 16, 2021

DOI: 10.21428/6ffd8432.49c5c842

License: Creative Commons Attribution 4.0 International License (CC-BY 4.0). 


\section{1 | Context}

Colombia is a Latin American country considered as one of the middle income countries of the Global South (World Bank,_2021). Since 2017 almost 60 higher education institutions and universities started a collective negotiation of the "big deals" with 5 publishers: Elsevier, Springer, Oxford University Press, Taylor \& Francis and SAGE. This collective negotiation was part of a national strategy that was seeking to overcome the national agreement in Colombia with only one publisher: Elsevier. These 60 institutions formed the Consorcio Colombia group with the logistical operation of Consortia S.A.S and the support of the Colombian Association of Universities (ASCUN), the Ministry of Education (MEN) and the Ministry of Science and Technology (Minciencias), and made a first general negotiation with three principal goals: (i) have a diversification of academic publishers in Colombia, (ii) get discounts and improve equity in access to academic production, especially for smaller academic institutions, and (iii) create a participation space to analyze, discuss and think about new scenarios in scholarly publishing and communication.

The institutions which belong to the Consorcio Colombia belong to all regions of our country and are represented by library directors, vice presidents for academic or vice presidents for research. All the members have an official designation from their academic institutions and the group is characterized by a plural representation that has permitted an important level of engagement and organization. The representation is decided in a general council considering the different types of institutions (universities and research centers) and country regions. A study carried out by the same members of the Consortium allowed the classification of the institutions into 4 groups, according to their size and maturity in research. Each group participates in the Consortium with differentiated prices and scopes. (Consorcio Colombia, 2021). The Consorcio Colombia has not only functions of negotiation but have also formed 11 commissions with academic and communicative purposes. 


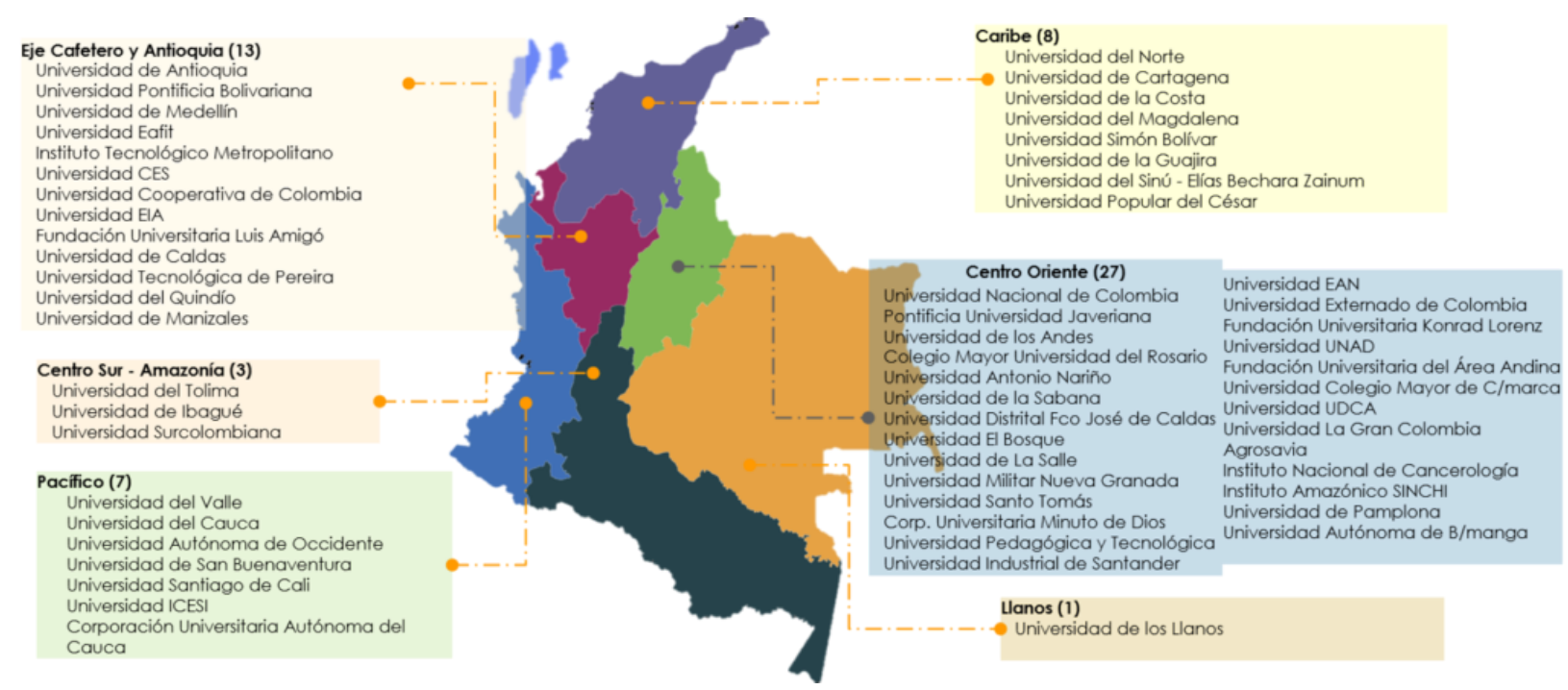

Consorcio Colombia (2021) Members by region

\section{2 | Challenges in the subscription-based model: a lack of a policy of financing}

Currently in Colombia the investment in subscriptions comes directly from academic institutions. The official funding from the government constitutes no more than $20 \%$, and this $20 \%$ is a compensation only to the institutions who are part of the Consorcio Colombia and it must be requested every year. Since there is not a governmental policy to finance publishing in Colombia the changes in political administration could affect collective initiatives like the consortium. In contrast, an increasing number of institutions are adopting Open Access policies and improving their repositories, Open Journal Systems (OJS), and open data initiatives.

To understand how Open Access is considered in Colombia - and in general in Latin America - we have to make a difference between 1) the Green Open Access initiatives led by $\underline{\text { Scielo }}$ Redaly $\underline{\text { R }}$ and La Referencia; ; and 2) the Open Access discussions which are derived from Article Processing Charges (APC) payments and Transformative Agreements (TA) in the gold and hybrid open access routes.

The majority of the Colombian institutions have and manage by themselves OA journals published in institutional OJS and Repositories. These journals are totally financed by institutions, written in Spanish and generally indexed in Scielo or Redalyc. Sometimes, with big difficulties, they are indexed in Scopus and Web of Science (Espinosa \& Insuaty-Rodríguez,2015). The indexation policies are under discussion, 
and publishing or not in indexed journals has obscured the discussion about the relevance of open dissemination, open access, open science, citizen science and international cooperation. There is a big disagreement about whether publishing in an

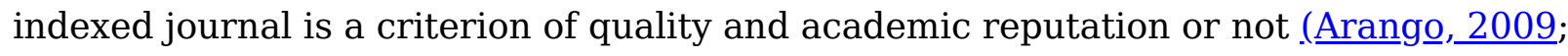
Uribe-Tirado, 2017). These OA journals are mostly in Spanish, a difficult point if we consider that English is the vehicular language. The language of publication has also been part of differences, sometimes related with the idea of cultural colonialism (Arias, J. D, et al.,2020). This point needs to be deeper understood in a current open discussion about fair and equitable practices in publishing, which entail not only economical but also communicative and cultural factors.

The discussion about OA via transformative agreements, gold, and hybrid routes has been recently taken into account by the Consorcio Colombia in their negotiations with Elsevier, Springer, Taylor \& Francis, Oxford University Press, and SAGE. The first discussion was raised in 2018 without an answer from any publisher. After this first discussion, a special commission from the Consorcio Colombia and the CoLav Laboratory from the University of Antioquia made a general study to determine the APC payment behaviour in the Colombian institutions from 2009 to 2019 (VélezCuartas et al.,2020). This study showed that even in the context of green open access in Latin America, institutions were paying APCs, starting in 2009 with $11 \%$ of products published OA with publishers like Elsevier and up to 25\% in 2019. Determining where the APC comes from is a big challenge because most of the institutions do not register these transactions and some authors pay the APC by themselves. 


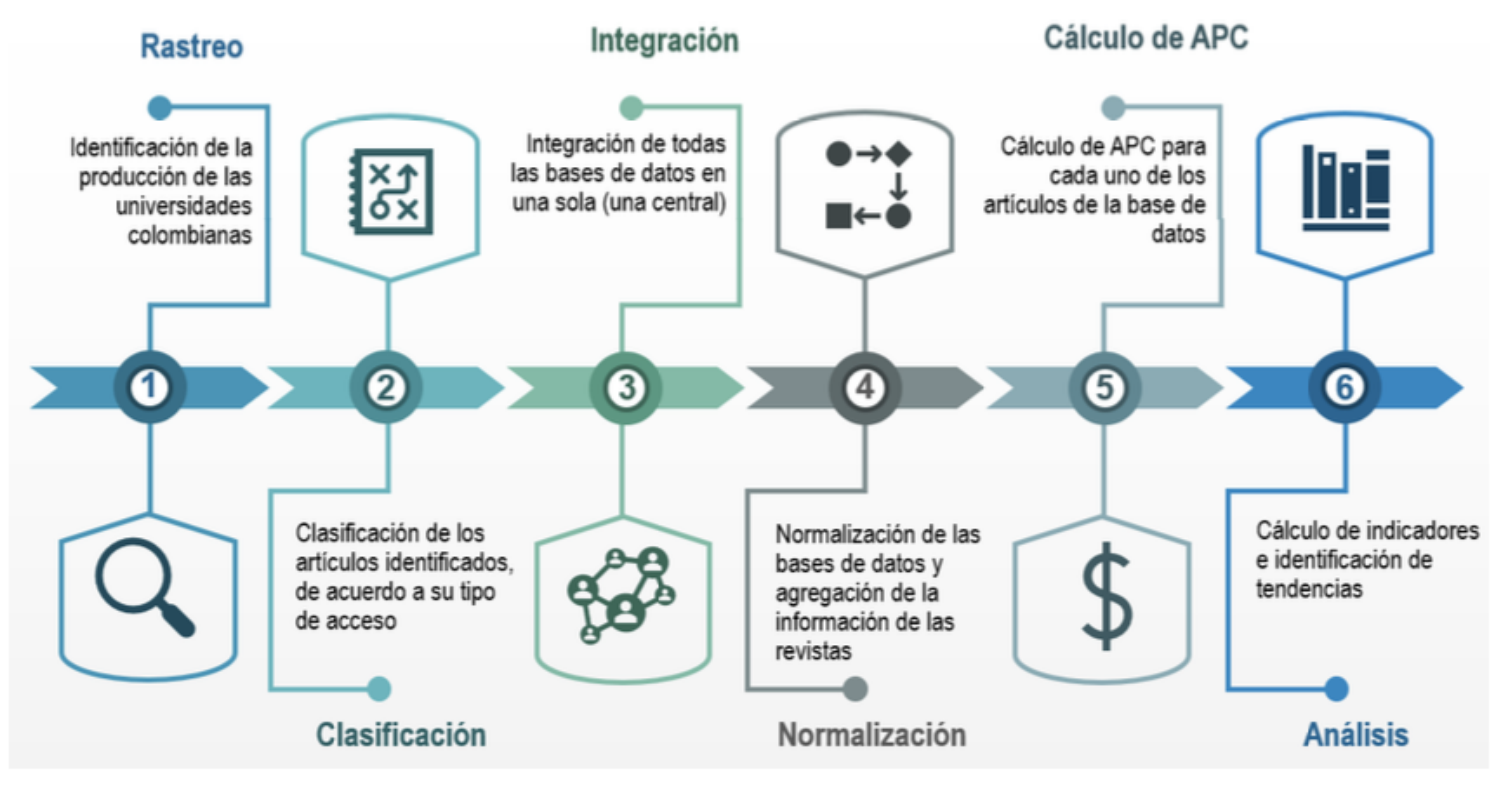

Colav and Consortia (2021) Methodology

The CoLav's study had an immediate effect in our country and Consorcio Colombia made in 2020 pre-payment agreements with discounts in APC payments with Oxford University Press, Taylor \& Francis, Springer, and Sage. We did not reach a prepayment agreement with Elsevier at that time and we only received proposals for future pilots.

During this year we have been working on a Transformative Agreement model after analyzing the ESAC initiative documentation, the different TA models and with the support and advice of the Max Planck Institute, and other international institutions. We began the discussion by looking for a TA with Elsevier, Springer, and Taylor \& Francis in October 2021. The Consorcio Colombia studied and compared principles recommended in other negotiations (ESAC,2021). and considered the Guideline to Open Access (Colciencias, 2018) from the Ministry of Science of Colombia. After that, it identified the following principles:

- Sustainability

- Equity / Diversity

- Transparency / Integrity

- Accessibility / Openness

- Quality

- Collaboration / Reciprocity 


\section{- Efficiency}

We have held that if the Colombian authors have been paying APC in the context of a subscription-based system, the publishers have to recognize that APC-based models are affecting our country's publishing behaviour and opportunities. This year the Consortium invite Elsevier, Springer and Taylor \& Francis to engage with a Read \& Publish agreement (still open and under discussion) to guarantee:

- No double-dipping

- APC cost adapted to our economies

- Concerted workflows with the institutions

- The recognition of our diversity conditions

- A concerted transition to OA

Another relevant factor is that a supportive culture surrounding APC payment and TAs is needed, along with details about what they entail and when they are justified. Some libraries, researching institutions, and authors pay APCs without a clear awareness of what they are. In answer to this situation, the Consorcio Colombia has led some events like the $A B C$ of Open Access, meetings about alternative and responsible metrics and is looking for a general TA. For the next year we are planning a training agenda for librarians, research leaders, and editors about gold routes to open access and their institutional and communicative implications.

On the other hand, our libraries and institutions do not have a tradition of paying and financing open access in gold routes, and the collections budgets have been historically used to pay for reading not for publishing. This custom has naturalized a model in which the institutions always pay to read as a consumer but never to transform reading into publishing as part of an initiative to move to open access, open science, and a more equitable and plural scientific communication. In this same way the libraries and researching teams need to think again about their roles in the academic reading and publishing circuit.

From the publisher's side, the OA teams are just starting negotiations with the Global South institutions and, generally, do not belong from our countries or academies. This entails difficulties as well as advantages. The first of them is the little knowledge about the economic and cultural particularities of our countries, which require an effort in knowing our political and institutional culture. A very interesting challenge in the future is how publishers and institutions will train people to navigate this global landscape of local cultural differences and expectations. 


\section{3 | The inequities of the subscription-based system}

Finally, I would like to mention some inequities I find in the subscription-based system in a country like mine and some assumptions about publishing which could endanger a better engagement with open access initiatives:

- We pay in dollars, but our budgets are in Colombian pesos, which is a relatively weak currency with significant variations.

- We do not have clear and fixed funders. Institutional and governmental funding do not increase and we mostly spend budgets on subscriptions. This constitutes a vicious cycle because if we spend everything on subscribing, then we will not be able to move our production towards open access.

- The Colombian academic institutions must define policies for APC payments. There are diverse and under-registered payment methods that make the actual cost of APCs difficult to track precisely. Our institutions have challenges in formalization and instituting better publishing registration systems.

- The TA movement needs to consider the effect of the open access initiatives globally. Our authors want to publish in OA because of its advantages or the cooperation needed in the international collaborations, but the models of these transitions have been built in the Global North with its conditions and needs in mind. There are some studies about the effect of TA in lower-income countries (․ Harle and Warne, 2020; Taubert et al.,2021), however there are middle-income countries like Colombia with great inequities in the distribution of resources in education and research, which are not eligible for deep discounts and waivers but do not receive more resources than they currently have. We must overcome the vicious cycle of economic indicators and consider the real distributions of resources in our countries for science and technology. I think it is important to change these criteria with adaptable initiatives proposed by us in consensus with publishers. Some examples of the effect of these economic indicators as a debatable criterion of equity could be found in APC waivers and discounts (ㅁpringer, 2021) and Choice Select: the publishing model that's right for you (Elsevier, 2021).

- There is an idea, surely prejudiced, of Colombia as an academic consumer not a partner or a producer. This idea has led publishers to naturalize our needs as the needs of a reader, not the needs of a country looking for better channels to disseminate and communicate its science and research. Our institutions are just 
looking to close the gaps in access to knowledge and exercise the right to universal academic communication from our circumstances.

\section{Citations}

1. World Bank (2021) The World Bank in Middle Income Countries, Retrieved 10 23, 2021, from https://www.worldbank.org/en/country/mic $\leftrightharpoons$

2. Espinosa \& Insuasty-Rodriguez (2015). “El conocimiento inventariado. Apuntes críticos sobre el modelo de indexación de las publicaciones académicas en Colombia". In: Ágora. Retrieved 10 23, 2021, from http://www.scielo.org.co/pdf/agor/v15n1/v15n1a05.pdf $ヒ$

3. Arango, Pablo Rolando (2009). "La farsa de las publicaciones universitarias". In: El Malpensante. Retrieved 10 23, 2021, from https://elmalpensante.com/articulo/1031/la-farsa-de-las-publicaciones-universitarias $\triangleq$ 4. Uribe-Tirado (2017). "Publindex se usa como no se debe". In: Alma mater. Retrieved 10 23, 2021, from http://bibliotecadigital.udea.edu.co/bitstream/10495/12607/1/UribeAlejandro 2017 P $\underline{\text { ublindexUso.pdf }} \leftrightharpoons$

5. Arias, J. D, et al. (2020). Aproximaciones contextuales sobre el devenir de las revistas contables colombianas. Perspectivas plurales de los editores. Contaduría Universidad de Antioquia, 77, 131-165. Doi: https://doi.org/10.17533/udea.rc.n77a05

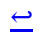

6. Vélez-Cuartas, G., Restrepo-Quintero, D., Uribe-Tirado, A., Gutiérrez, G., ZapataMesa, O., Pallares, C., \& Suárez-Tamayo, M. (2020). Identificación de pagos de APC por parte de las instituciones de educación superior (IES) colombianas. Énfasis en las pertenecientes al Consorcio Colombia. Eprints. Retrieved 10 23, 2021, from http://eprints.rclis.org/40494/

7. ESAC (2021) Negotiation principles internationally, Retrieved 10 23, 2021, from https://esac-initiative.org/guidelines/ $\leftrightharpoons$

8. Colciencias. (2018) Lineamientos para una política de Ciencia Abierta en Colombia, from

https://minciencias.gov.co/sites/default/files/ckeditor files/Lineamientos\%20ciencia\% 20abierta\%2017-dic-2018-doc.pdf 
9. Harle, J., \& Warne, V. (2020). Open Access: challenges and opportunities for Lowand Middle-Income Countries and the potential impact of UK policy. www.inasp.info $\underline{.}$

10. Taubert, N., Bruns, A., Lenke, C., \& Stone, G. (2021). Waiving article processing charges for least developed countries: a keystone of a large-scale open access transformation. Insights, 34(1). https://doi.org/10.1629/UKSG.526 $\leftrightharpoons$

11. Springer (2021). APC waivers and discounts, Retrieved 1023,2021 , from https://www.springernature.com/br/open-research/policies/journal-policies/apcwaiver-countries $\subseteq$

12. Elsevier (2021). Choice: Select the publishing model that's right for you, Retrieved 10 23, 2021, from https://www.elsevier.com/authors/open-access/choice $\leftrightharpoons$ 